\title{
Physical Activity in Early Adolescence and Pulmonary Function Gain From 15 to 18 Years of Age in a Birth Cohort in Brazil
}

\author{
Bruna Gonçalves Cordeiro da Silva, Fernando César Wehrmeister, Philip H. Quanjer, \\ Rogelio Pérez-Padilla, Helen Gonçalves, Bernardo Lessa Horta, Pedro Curi Hallal, \\ Fernando Barros, and Ana Maria Baptista Menezes
}

\begin{abstract}
Background: The aim of this study was to evaluate the association between physical activity from 11 to 15 years of age and pulmonary function (PF) gain from 15 to 18 years of age among adolescents in a birth cohort in Brazil. Methods: Longitudinal analysis of the individuals participating in the 1993 Pelotas Birth Cohort Study. Physical activity was assessed by self-report at ages 11 and 15, spirometry was performed at ages 15 and $18(\mathrm{n}=3571)$. Outcome variables assessed were gains in forced expiratory volume in 1 second $\left(\mathrm{FEV}_{1}\right)$, forced vital capacity (FVC) and peak expiratory flow (PEF). Crude and adjusted linear regressions, stratified by sex, and mediation analyses were performed. Results: Boys who were active (leisure-time and total physical activity) at ages 11 and 15 had higher gains in $\mathrm{FEV}_{1}, \mathrm{FVC}$, and PEF than those who were inactive. Vigorous-intensity physical activity in boys was also associated with $\mathrm{FEV}_{1}$ and FVC gains. Mediation analyses showed that height at age 18 accounted for $5 \%$ to $75 \%$ of the association between physical activity and PF gains. No significant associations were found among girls. Conclusions: Physical activity in early adolescence is associated with gains in PF by the end of adolescence in boys.
\end{abstract}

Keywords: respiratory health, health, adolescent, epidemiology

The negative association between physical activity and many noncommunicable diseases has been widely researched., ${ }^{1,2}$ Furthermore physical activity has also been shown to have negative associations with all-cause mortality. ${ }^{3}$ Nevertheless, physical activity levels remain below recommended levels both in adults and in adolescents worldwide, including rapidly developing countries such as Brazil. ${ }^{4,5}$ A population-based study carried out in a representative sample of Brazilian households observed that only $16.1 \%$ of individuals in the age range of 14 to 24 years were physically active during leisure time. ${ }^{5}$

Studies on physical activity and pulmonary function (PF) are scarce. However, reduced PF has been shown to increase the risk not only to respiratory disorders, but also for all-cause, cancer, respiratory, and cardiovascular mortality. ${ }^{6,7}$ Moreover, reduced PF during childhood is associated with increased mortality risk in adulthood. ${ }^{8}$ Most studies assessing the effect of physical activity on PF have been conducted only in specific subpopulations such as smokers, individuals with asthma, or individuals with COPD, ${ }^{9-11}$ or only investigated the association between physical activity and PF decline in adults. ${ }^{12,13}$ Few studies on this subject have been conducted in adolescents. ${ }^{14-16}$ Therefore, the relationship between physical activity and PF in adolescence remains understudied.

Furthermore, to date there have been no population based longitudinal studies evaluating the relationship between physical

da Silva, Wehrmeister, Gonçalves, Horta, Hallal, and Menezes are with the Postgraduate Program in Epidemiology, Federal University of Pelotas, Pelotas, Brazil. Quanjer is with the Dept of Paediatrics-Pulmonary Diseases, Erasmus Medical Centre, Erasmus University, Rotterdam, The Netherlands. Pérez-Padilla is with the Institute of Respiratory Diseases, Mexico City, Mexico. Barros is with the Postgraduate Program in Health and Behavior, Catholic University of Pelotas, Pelotas, Brazil. da Silva (brugcs@ @otmail. com) is corresponding author. activity in early adolescence and PF in late adolescence. Thus, we evaluated the association between physical activity from 11 to 15 years of age and PF gain from 15 to 18 years of age in a population based sample of adolescents from southern Brazil.

\section{Methods}

\section{Study Design and Participants}

In 1993, the mothers of all hospital-born children living in the urban area of Pelotas were invited to participate in the 1993 Pelotas Birth Cohort Study. Of the 5265 live births occurring in Pelotas in 1993, 5249 mothers $(99.7 \%)$ agreed to participate. Mothers were interviewed in the hospital soon after delivery by trained interviewers on demographic, socioeconomic, and behavioral factors. Follow-up visits were conducted in 2004, 2008, and 2011 when the children had reached the mean ages of 11,15 , and 18 years, respectively. At each follow-up the adolescents were interviewed for behavioral and health factors. Furthermore, at the 2008 and 2011 visits, spirometry was performed on all participants. All visits of the 1993 Pelotas Birth Cohort Study were approved by the Ethics Committee of the Medical School of the Federal University of Pelotas. At each visit participants signed a written informed consent. If participants were younger than 18 years of age, the consent form was signed by a parent or guardian. Further details on the study methodology are published elsewhere. ${ }^{17,18}$

\section{Exposure and Outcome Variables}

The same spirometry protocol was performed when the participants were 15 and 18 years old. All procedures were carried out with the subjects sitting with their backs straight while wearing a noseclip. The spirometry was carried out by a trained technician and under the supervision of an expert researcher. At least 3 acceptable 
spirometry maneuvers were obtained of each participant and the best maneuver was used. A battery-operated portable spirometer (Easy-One; NDD Medical Technologies, Chelmsford MA, USA and Zurich, Switzerland) was used. Those who had undergone abdominal, eye, or thoracic surgery or had any hospital admissions in the previous 3 months or those with heart disease were excluded from spirometry. In addition, those who were undergoing tuberculosis treatment or who were pregnant or thought to be pregnant were also excluded. A total of 3571 individuals participated in a full analysis at the 2008 and 2011 visits respectively. The criteria of the American Thoracic Society (ATS) and European Respiratory Society (ERS) were applied to maintain the quality standard of the spirometry curves. ${ }^{19}$ In both follow-up visits, approximately $90 \%$ of the procedures met the acceptability and reproducibility criteria proposed. Spirometry was performed pre and postbronchodilator at both ages, although only prebronchodilator tests were used in the current study.

Gains in PF were assessed through gains in $\mathrm{FEV}_{1}$ (forced expiratory volume in 1 second), FVC (forced vital capacity), and PEF (peak expiratory flow), calculated as the difference between these parameters at 15 and 18 years of age. Gains in PF were expressed as z-scores, which were generated from the standardized residuals of the study sample at 15 and 18 years old separately, taking into account sex, skin color, and height. These equations were chosen since none of the equations available in the literature were adequate for our sample..$^{20,21}$

During the 2004 and 2008 visits, when the participants were on average 11 and 15 years old respectively, physical activity was self-reported through questionnaires regarding the duration and weekly frequency of leisure-time and commuting physical activity. The questionnaire included a list of activities constructed on a pilot study identifying the most frequent activities practiced at each age. Individuals achieving 300 minutes or more of weekly physical activity were classified as active while those not reaching this threshold were classified as inactive. ${ }^{22}$ This classification was used for leisure-time and total physical activity (leisure and commuting). Self-reported physical activity was also classified as moderate or vigorous in intensity based on the Compendium of Physical Activity. ${ }^{23}$ For moderate- and vigorous-intensity physical activity, cut-off points of 150 minutes and 75 minutes per week respectively were used to classify individuals as active or inactive. Active periods between ages 11 and 15 were divided in 3 categories: never active, active at one age, and always active.

\section{Statistical Analysis}

All analyses were conducted using Stata 12.0 (StataCorp, College Station, TX, USA). Crude and adjusted linear regression analyses were performed to assess the association between physical activity at ages 11 and 15 and PF gains from ages 15 to 18. Multivariate models were adjusted for skin color (self-reported) as marker of ethnicity, pubic hair development at age 15 (according to the Tanner scale), self-reported wheezing in the previous 12 months at age 15 , and self-reported smoking at age 15 (one or more cigarettes in the previous month). In addition, models were adjusted for maternal self-reporting of family income at birth, maternal schooling, maternal smoking during pregnancy, mother's height at birth as well as weight at birth of the neonate, participant body mass index (BMI) at ages 11 and 15 and participant height at age 15 years. Mediation analyses were performed for statistically significant associations in the adjusted model using G-computation to verify the proportion of the association between physical activity and PF captured by height at age 18 years. This was done by estimating the natural direct effects (NDE) and natural indirect effects (NIE) of physical activity on PF gain. Mediation analyses were adjusted for the same confounding factors used in the regression analyses and as well as BMI at age 18 years as post confounding variable according to the analytical model (Figure 1). Given the significant

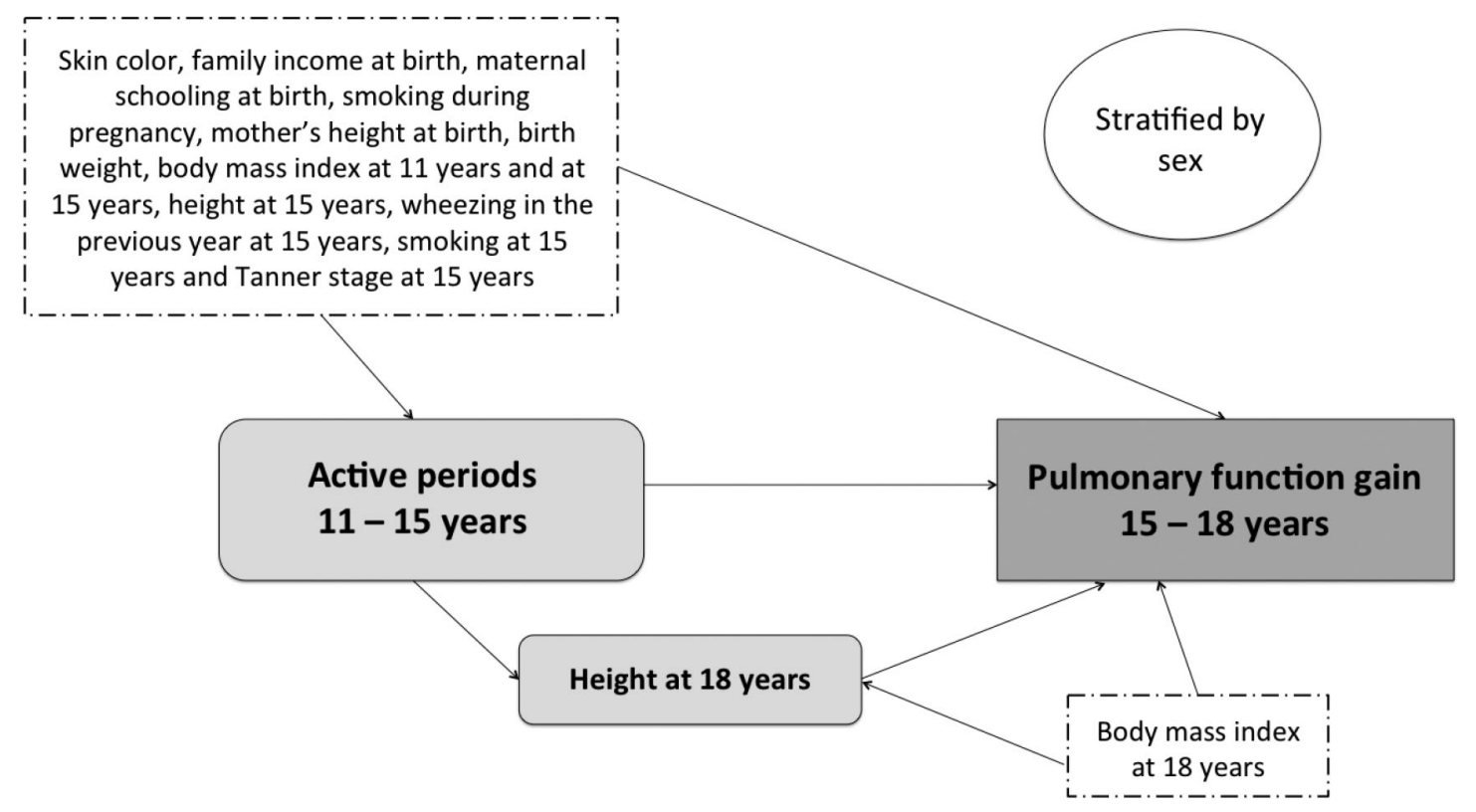

Figure 1 - Mediation analysis model. 
interactions between physical activity and sex in predicting gains in PF all analyses were stratified by sex.

\section{Results}

At ages 11,15 , and $18,87.5 \%, 85.7 \%$, and $81.3 \%$ of the original birth cohort were followed up, respectively. Table 1 describes anthropometric characteristics, physical activity changes from 11 to 15 years of age, and PF at 15 and 18 years of age. In general, boys had higher levels of physical activity than did girls. In both periods, boys were about 4 times more active than girls with regard to leisuretime physical activity and 2.5 times more active with regard to total physical activity. Slightly less than half of boys (44\%) engaged in vigorous-intensity physical activity at ages 11 and 15 . Conversely, the majority of girls (71.6\%) were inactive at both ages. Overall, there was a higher participation by girls in moderate-intensity as compared with vigorous-intensity physical activity than boys at both ages. With regard to overall PF parameters, at both ages, boys had higher mean $\mathrm{FEV}_{1}, \mathrm{FVC}$, and PEF values, as well as higher mean absolute PF gains than did girls.

Leisure-time physical activity was associated with higher gains in $\mathrm{FEV}_{1}, \mathrm{FVC}$, and PEF between the ages of 15 and 18 years among boys in both crude and adjusted analyses (Table 2). In the adjusted analyses, only those boys who were classified as active in leisure-time physical activity at both ages showed higher gains in all $3 \mathrm{PF}$ parameters compared with those who were classified as inactive. Total and vigorous-intensity physical activity were also significantly associated with PF gains and boys who were classified as always active showed significantly higher gains than those classified as never active, aside from the association between vigorous-intensity physical activity and PEF gain, which was not significant. Furthermore, no significant association was found between moderate-intensity physical activity and overall PF gain. In practical terms, boys who were classified as always active in leisure-time physical activity had increases of $13 \%, 8.6 \%$, and $20 \%$ in $\mathrm{FEV}_{1}, \mathrm{FVC}$, and PEF, respectively, compared with the average increase for all boys from this cohort, even after adjusting for confounding factors. For total physical activity, boys classified as always active showed an increase of $10.1 \%, 6.7 \%$, and $14.8 \%$ in $\mathrm{FEV}_{1}, \mathrm{FVC}$, and PEF, respectively, compared with the average PF gain for boys from this cohort. Regarding vigorous-intensity physical activity, always-active boys had $10 \%$ increase in $\mathrm{FEV}_{1}$ and $6.6 \%$ increase in FVC compared with the average increase for the sample (data not shown). For girls, no significant association was found between active periods from 11 to 15 years of age and PF gain between the ages of 15 to 18 (Table 3).

Mediation analyses showed that with regard to boys, height at age 18 was responsible for between $25.9 \%$ and $41.3 \%$ of the association between leisure-time physical activity and PF gain (Figure 2) and between $58.3 \%$ and $74.8 \%$ of the association between vigorousintensity physical activity and PF gain (Figure 3 ). Moreover, height at 18 years was also responsible for between 5\% and 36.3\% of the association between total physical activity and PF gain (Figure 4).

\section{Discussion}

The results of this prospective longitudinal analysis demonstrated consistent associations between physical activity between the ages of 11 to 15 and gains in $\mathrm{FEV}_{1}, \mathrm{FVC}$, and PEF between the ages of 15 to 18 in adolescent boys from a large cohort in southern Brazil. Even after adjusting for several confounding factors and including height as a mediator of the association, leisure-time, total, and vigorous-intensity physical activity was significantly associated with PF gain. However, no such results were found for girls in the same cohort.

Previous studies in adults assessing the relationship between physical activity and PF have reported positive associations. ${ }^{12,13}$ The data in children and adolescents, however, remains conflicting. Some cross-sectional studies conducted found no evidence of an association between physical activity and $\mathrm{PF}_{15,24}$ but a Norwegian study conducted in 9- and 10-year-old children reported that girls who were more active had higher $\mathrm{FEV}_{1}$ and $\mathrm{FVC}$ values..$^{25}$ In addition, a longitudinal assessment of individuals between the ages of 13 and 27 in the Netherlands reported associations between physical activity and FVC, but an inverse association with PEF. ${ }^{14}$ Furthermore, a recent study from Chinese that followed participants from ages 9 to 11 years reported that active girls had higher PF values and higher PF growth rates than those who were inactive. ${ }^{26}$ Similarly, a prior study of the 1993 Pelotas Birth Cohort found that, compared with inactive girls at ages 11 and 15 , those who were active at both ages had larger $\mathrm{FVC}$ and $\mathrm{FEV}_{6}$ values at age 15 years. ${ }^{16} \mathrm{~A}$ possible explanation for the contradictory findings in the literature may be the result of the differing ages at which PF was evaluated as well as the variations between the cross-sectional or longitudinal study designs. Unlike previous studies, in the current study significant associations between early adolescent physical activity and later adolescent PF gains were found only in boys. This may be due to the notion that unlike girls, boys experience rapid growth between the ages of 15 and $18 .{ }^{27}$ This is evidenced by the height gain in boys between the second and third follow-up which was much more significant than that of the girls (data not shown), whose gain usually takes place at earlier ages. ${ }^{27}$ As a result, girls would be less likely to have gains in PF after age 15 years. It is possible that if PF data were collected for girls in early adolescence significant associations may have been found.

The results of our study noted a dose-response relationship between early adolescent physical activity in boys and later adolescent gains in PF. It was also observed that boys who were only active at age 11 had greater PF gains than those who were never active at either age, even after adjusting for confounding factors (Figure 5). Conversely, boys who were only active at age $15 \mathrm{did}$ not have increased gains in PF compared with those who were never active at either age. These results highlight the importance of physical activity in early adolescence to maximize later PF gains. Moreover, these results highlight the importance of maintaining physical activity during adolescence given that boys who remained active at both periods had larger PF gains at the end of adolescence.

In general, the present results were stronger for leisure-time and vigorous-intensity physical activity (except for PEF gain). These results were expected since leisure-time physical activity is more intense and, similarly to vigorous-intensity physical activity, it is usually practiced in a more regular and standardized way. ${ }^{28,29}$ In addition, the fact that no associations were found for moderateintensity physical activity suggests the importance of physical activity intensity in obtaining benefits for PF.

Concerning the clinical meaning of the regression coefficients, it was observed that always-active boys showed greater PF gains compared with the overall average for boys. The values ranged from $6.6 \%$ to $20 \%$ over the average PF gain. These findings point to a possible clinical significance of physical activity during adolescence and PF gain.

Regarding the biological plausibility of this association, although the mechanisms through which physical activity would 
Table 1 Description of Anthropometric Characteristics, Physical Activity Changes (Ages 11-15 Years), and Pulmonary Function Parameters at Ages 15 and 18 Years, by Sex

\begin{tabular}{|c|c|c|}
\hline Variable & Male & Female \\
\hline Height at 15 years, cm (Mean [SD]) & $167.16(8.05)$ & $159.22(6.30)$ \\
\hline Height at 18 years, cm (Mean [SD]) & $173.77(6.95)$ & $161.05(6.41)$ \\
\hline Body mass index at 11 years, $\mathrm{kg} / \mathrm{cm}^{2}$ (Mean [SD]) & $18.56(3.54)$ & $18.56(3.60)$ \\
\hline Body mass index at 15 years, $\mathrm{kg} / \mathrm{cm}^{2}$ (Mean [SD]) & $21.36(3.99)$ & $21.58(3.94)$ \\
\hline Body mass index at 18 years, $\mathrm{kg} / \mathrm{cm}^{2}$ (Mean [SD]) & $23.37(4.24)$ & $23.52(4.76)$ \\
\hline \multicolumn{3}{|l|}{ Active periods in leisure-time PA (N [\%]) } \\
\hline Never active & $548(27.1)$ & $1210(57.7)$ \\
\hline Active once & $896(44.2)$ & $729(34.8)$ \\
\hline Always active & $580(28.7)$ & $157(7.5)$ \\
\hline \multicolumn{3}{|l|}{ Active periods in total PA $(\mathrm{N}[\%])$} \\
\hline Never active & $375(18.7)$ & $908(43.5)$ \\
\hline Active once & $839(41.7)$ & $844(40.4)$ \\
\hline Always active & $797(39.6)$ & $335(16.1)$ \\
\hline \multicolumn{3}{|l|}{ Active periods in moderate-intensity PA (N [\%]) } \\
\hline Never active & $674(33.3)$ & $507(24.2)$ \\
\hline Active once & $887(43.9)$ & $880(42.1)$ \\
\hline Always active & $462(22.8)$ & $705(33.7)$ \\
\hline \multicolumn{3}{|l|}{ Active periods in vigorous-intensity PA (N [\%]) } \\
\hline Never active & $362(17.9)$ & $1499(71.6)$ \\
\hline Active once & $770(38.1)$ & $518(24.8)$ \\
\hline Always active & $889(44.0)$ & $76(3.6)$ \\
\hline \multicolumn{3}{|l|}{ Active once in leisure-time PA (N [\%]) } \\
\hline Only active at 11 years & $385(19.0)$ & $413(19.7)$ \\
\hline Only active at 15 years & $511(25.3)$ & $316(15.1)$ \\
\hline \multicolumn{3}{|l|}{ Active once in total PA ( $\mathrm{N}[\%])$} \\
\hline Only active at 11 years & $378(18.8)$ & $467(22.4)$ \\
\hline Only active at 15 years & $461(22.9)$ & $377(18.1)$ \\
\hline \multicolumn{3}{|l|}{ Active once in moderate-intensity PA (N [\%]) } \\
\hline Only active at 11 years & $526(26.0)$ & $508(24.3)$ \\
\hline Only active at 15 years & $361(17.8)$ & $372(17.8)$ \\
\hline \multicolumn{3}{|l|}{ Active once in vigorous-intensity PA (N [\%]) } \\
\hline Only active at 11 years & $376(18.6)$ & $334(16.0)$ \\
\hline Only active at 15 years & $394(19.5)$ & $184(8.8)$ \\
\hline $\mathrm{FEV}_{1}$ at 15 years, $\mathrm{L}$ (Mean $\left.[\mathrm{SD}]\right)$ & $3.46(0.66)$ & $2.93(0.44)$ \\
\hline FVC at 15 years, L (Mean [SD]) & $4.01(0.76)$ & $3.30(0.51)$ \\
\hline $\mathrm{PEF}$ at 15 years, L/s (Mean [SD]) & $7.47(1.45)$ & $6.61(1.04)$ \\
\hline $\mathrm{FEV}_{1}$ at 18 years, $\mathrm{L}$ (Mean $\left.[\mathrm{SD}]\right)$ & $4.12(0.62)$ & $3.04(0.45)$ \\
\hline FVC at 18 years, L (Mean [SD]) & $4.80(0.71)$ & $3.50(0.51)$ \\
\hline PEF at 18 years, L/s (Mean [SD]) & $8.76(1.54)$ & $6.47(1.17)$ \\
\hline $\mathrm{FEV}_{1}$ gain, L (15-18 years) (Mean $\left.[\mathrm{SD}]\right)$ & $0.64(0.47)$ & $0.10(0.25)$ \\
\hline FVC gain, L (15-18 years) (Mean [SD]) & $0.78(0.46)$ & $0.19(0.29)$ \\
\hline PEF gain, L/s (15-18 years) (Mean [SD]) & $1.29(1.28)$ & $-0.11(0.89)$ \\
\hline
\end{tabular}

Abbreviations: PA, physical activity; $\mathrm{FEV}_{1}$, forced expiratory volume in 1 second; FVC, forced vital capacity; PEF, peak expiratory flow. 
Table 2 Crude and Adjusted Analyses of Active Periods From Ages 11 to 15 Years and Pulmonary Function Gain (z-Score Values) From Ages 15 to 18 Years in Male Subjects

\begin{tabular}{|c|c|c|c|c|}
\hline \multirow[b]{2}{*}{ Variable } & \multicolumn{2}{|r|}{ Crude } & \multicolumn{2}{|r|}{ Adjusted $^{*}$} \\
\hline & Mean & $\beta(95 \% \mathrm{Cl})$ & Mean & $\beta(95 \% \mathrm{Cl})$ \\
\hline \multicolumn{5}{|l|}{$\mathrm{FEV}_{1}$ gain (z-score) } \\
\hline Leisure-time PA & & $P=.001$ & & $P=.002$ \\
\hline Never active & -0.115 & Ref & -0.092 & Ref \\
\hline Active once & -0.003 & $0.112(0.014,0.210)$ & 0.003 & $0.095(-0.009,0.199)$ \\
\hline Always active & 0.075 & $0.190(0.083,0.297)$ & 0.085 & $0.177(0.063,0.290)$ \\
\hline Total PA & & $P=.004$ & & $P=.018$ \\
\hline Never active & -0.102 & Ref & -0.077 & Ref \\
\hline Active once & -0.032 & $0.070(-0.043,0.182)$ & -0.020 & $0.057(-0.062,0.175)$ \\
\hline Always active & 0.056 & $0.158(0.044,0.271)$ & 0.060 & $0.137(0.017,0.258)$ \\
\hline Moderate-intensity PA & & $P=.322$ & & $P=.301$ \\
\hline Never active & -0.029 & Ref & -0.027 & Ref \\
\hline Active once & -0.016 & $0.013(-0.079,0.105)$ & 0.005 & $0.031(-0.067,0.130)$ \\
\hline Always active & 0.027 & $0.057(-0.052,0.165)$ & 0.034 & $0.061(-0.055,0.176)$ \\
\hline Vigorous-intensity PA & & $P=.006$ & & $P=.025$ \\
\hline Never active & -0.111 & Ref & -0.090 & Ref \\
\hline Active once & -0.028 & $0.083(-0.033,0.199)$ & -0.010 & $0.080(-0.043,0.204)$ \\
\hline Always active & 0.043 & $0.154(0.042,0.267)$ & 0.046 & $0.136(0.016,0.257)$ \\
\hline \multicolumn{5}{|l|}{ FVC gain (z-score) } \\
\hline Leisure-time PA & & $P<.001$ & & $P=.002$ \\
\hline Never active & -0.119 & Ref & -0.086 & Ref \\
\hline Active once & -0.018 & $0.101(0.020,0.182)$ & -0.014 & $0.072(-0.011,0.156)$ \\
\hline Always active & 0.054 & $0.172(0.083,0.262)$ & 0.059 & $0.146(0.054,0.237)$ \\
\hline Total PA & & $P=.001$ & & $P=.017$ \\
\hline Never active & -0.122 & Ref & -0.079 & Ref \\
\hline Active once & -0.032 & $0.091(-0.003,0.184)$ & -0.027 & $0.051(-0.044,0.147)$ \\
\hline Always active & 0.032 & $0.154(0.060,0.249)$ & 0.034 & $0.113(0.016,0.210)$ \\
\hline Moderate-intensity PA & & $P=.210$ & & $P=.237$ \\
\hline Never active & -0.050 & Ref & -0.050 & Ref \\
\hline Active once & -0.020 & $0.029(-0.047,0.106)$ & 0.009 & $0.059(-0.020,0.138)$ \\
\hline Always active & 0.008 & $0.057(-0.033,0.147)$ & 0.001 & $0.051(-0.042,0.144)$ \\
\hline Vigorous-intensity PA & & $P=.002$ & & $P=.012$ \\
\hline Never active & -0.090 & Ref & -0.077 & Ref \\
\hline Active once & -0.063 & $0.027(-0.069,0.124)$ & -0.039 & $0.039(-0.061,0.138)$ \\
\hline Always active & 0.035 & $0.125(0.032,0.219)$ & 0.034 & $0.112(0.015,0.209)$ \\
\hline \multicolumn{5}{|l|}{ PEF gain (z-score) } \\
\hline Leisure-time PA & & $P=.002$ & & $P=.004$ \\
\hline Never active & -0.116 & Ref & -0.100 & Ref \\
\hline Active once & 0.003 & $0.120(0.005,0.235)$ & 0.013 & $0.113(-0.011,0.237)$ \\
\hline Always active & 0.081 & $0.198(0.072,0.324)$ & 0.101 & $0.202(0.066,0.338)$ \\
\hline Total PA & & $P=.043$ & & $P=.041$ \\
\hline Never active & -0.096 & Ref & -0.087 & Ref \\
\hline Active once & -0.009 & $0.087(-0.046,0.219)$ & -0.000 & $0.086(-0.056,0.228)$ \\
\hline Always active & 0.043 & $0.139(0.006,0.272)$ & 0.063 & $0.149(0.005,0.293)$ \\
\hline Moderate-intensity PA & & $P=.304$ & & $P=.264$ \\
\hline Never active & -0.010 & Ref & 0.002 & Ref \\
\hline Active once & -0.039 & $-0.030(-0.137,0.078)$ & -0.029 & $-0.031(-0.148,0.086)$ \\
\hline Always active & 0.067 & $0.077(-0.050,0.204)$ & 0.091 & $0.089(-0.049,0.227)$ \\
\hline Vigorous-intensity PA & & $P=.101$ & & $P=.191$ \\
\hline Never active & -0.049 & Ref & -0.029 & Ref \\
\hline Active once & -0.040 & $0.009(-0.127,0.145)$ & -0.022 & $0.006(-0.141,0.154)$ \\
\hline Always active & 0.042 & $0.091(-0.041,0.224)$ & 0.050 & $0.079(-0.065,0.223)$ \\
\hline
\end{tabular}

Abbreviations: PA, physical activity; $\mathrm{FEV}_{1}$, forced expiratory volume in 1 second; FVC, forced vital capacity; PEF, peak expiratory flow.

* Adjusted for skin color, family income at birth, maternal schooling at birth, birth weight, smoking during pregnancy, mother's height at birth, body mass index at 11 years, body mass index at 15 years, height at 15 years, wheezing in the previous year at 15 years, smoking at 15 years and Tanner stage at 15 years. $P$-value for linear trend. 
Table 3 Crude and Adjusted Analyses of Active Periods From Ages 11 to 15 Years and Pulmonary Function Gain (z-Score Values) From Ages 15 to 18 Years in Female Subjects

\begin{tabular}{|c|c|c|c|c|}
\hline \multirow[b]{2}{*}{ Variable } & \multicolumn{2}{|r|}{ Crude } & \multicolumn{2}{|r|}{ Adjusted $^{*}$} \\
\hline & Mean & $\beta(95 \% \mathrm{Cl})$ & Mean & $\beta(95 \% \mathrm{Cl})$ \\
\hline \multicolumn{5}{|l|}{$\mathrm{FEV}_{1}$ gain (z-score) } \\
\hline Leisure-time PA & & $P=.665$ & & $P=.802$ \\
\hline Never active & 0.002 & Ref & 0.001 & Ref \\
\hline Active once & 0.008 & $0.005(-0.053,0.064)$ & -0.005 & $-0.006(-0.064,0.053)$ \\
\hline Always active & 0.027 & $0.025(-0.081,0.132)$ & 0.031 & $0.030(-0.079,0.138)$ \\
\hline Total PA & & $P=.212$ & & $P=.403$ \\
\hline Never active & -0.024 & Ref & -0.020 & Ref \\
\hline Active once & 0.039 & $0.063(0.003,0.123)$ & 0.025 & $0.044(-0.016,0.105)$ \\
\hline Always active & 0.003 & $0.027(-0.052,0.107)$ & -0.002 & $0.018(-0.063,0.098)$ \\
\hline Moderate-intensity PA & & $P=.691$ & & $P=.720$ \\
\hline Never active & 0.008 & Ref & -0.003 & Ref \\
\hline Active once & 0.012 & $0.004(-0.065,0.074)$ & 0.013 & $0.016(-0.055,0.086)$ \\
\hline Always active & -0.005 & $-0.013(-0.086,0.060)$ & -0.013 & $-0.010(-0.084,0.064)$ \\
\hline Vigorous-intensity PA & & $P=.661$ & & $P=.838$ \\
\hline Never active & -0.004 & Ref & -0.007 & Ref \\
\hline Active once & 0.043 & $0.047(-0.017,0.110)$ & 0.035 & $0.042(-0.022,0.107)$ \\
\hline Always active & -0.087 & $-0.084(-0.237,0.070)$ & -0.109 & $-0.102(-0.258,0.054)$ \\
\hline \multicolumn{5}{|l|}{ FVC gain (z-score) } \\
\hline Leisure-time PA & & $P=.806$ & & $P=.715$ \\
\hline Never active & -0.002 & Ref & -0.008 & Ref \\
\hline Active once & 0.015 & $0.017(-0.041,0.075)$ & 0.007 & $0.015(-0.045,0.075)$ \\
\hline Always active & -0.048 & $-0.046(-0.152,0.060)$ & -0.062 & $-0.054(-0.164,0.056)$ \\
\hline Total PA & & $P=.812$ & & $P=.903$ \\
\hline Never active & -0.012 & Ref & -0.014 & Ref \\
\hline Active once & 0.019 & $0.030(-0.029,0.090)$ & 0.006 & $0.020(-0.041,0.082)$ \\
\hline Always active & -0.016 & $-0.005(-0.084,0.075)$ & -0.019 & $-0.005(-0.087,0.077)$ \\
\hline Moderate-intensity PA & & $P=.333$ & & $P=.458$ \\
\hline Never active & 0.023 & Ref & 0.008 & Ref \\
\hline Active once & -0.000 & $-0.023(-0.093,0.046)$ & -0.004 & $-0.012(-0.084,0.060)$ \\
\hline Always active & -0.014 & $-0.036(-0.109,0.036)$ & -0.020 & $-0.028(-0.103,0.047)$ \\
\hline Vigorous-intensity PA & & $P=.326$ & & $P=.303$ \\
\hline Never active & 0.006 & Ref & -0.000 & Ref \\
\hline Active once & -0.005 & $-0.012(-0.075,0.052)$ & -0.013 & $-0.013(-0.079,0.052)$ \\
\hline Always active & -0.087 & $-0.094(-0.246,0.059)$ & -0.101 & $-0.101(-0.259,0.057)$ \\
\hline \multicolumn{5}{|l|}{ PEF gain (z-score) } \\
\hline Leisure-time PA & & $P=.585$ & & $P=.157$ \\
\hline Never active & 0.030 & Ref & 0.039 & Ref \\
\hline Active once & 0.010 & $-0.020(-0.097,0.056)$ & -0.017 & $-0.056(-0.135,0.024)$ \\
\hline Always active & 0.006 & $-0.024(-0.164,0.115)$ & -0.025 & $-0.064(-0.210,0.083)$ \\
\hline Total PA & & $P=.829$ & & $P=.484$ \\
\hline Never active & 0.017 & Ref & 0.032 & Ref \\
\hline Active once & 0.026 & $0.009(-0.069,0.087)$ & 0.005 & $-0.027(-0.109,0.054)$ \\
\hline Always active & 0.026 & $0.009(-0.096,0.113)$ & 0.000 & $-0.032(-0.141,0.077)$ \\
\hline Moderate-intensity PA & & $P=.495$ & & $P=.467$ \\
\hline Never active & 0.055 & Ref & 0.043 & Ref \\
\hline Active once & 0.008 & $-0.048(-0.139,0.044)$ & 0.009 & $-0.033(-0.129,0.062)$ \\
\hline Always active & 0.018 & $-0.037(-0.133,0.058)$ & 0.004 & $-0.039(-0.139,0.061)$ \\
\hline Vigorous-intensity PA & & $P=.304$ & & $P=.077$ \\
\hline Never active & 0.033 & Ref & 0.034 & Ref \\
\hline Active once & 0.000 & $-0.032(-0.116,0.051)$ & -0.031 & $-0.065(-0.152,0.022)$ \\
\hline Always active & -0.048 & $-0.081(-0.282,0.120)$ & -0.088 & $-0.122(-0.332,0.088)$ \\
\hline
\end{tabular}

Abbreviations: PA, physical activity; $\mathrm{FEV}_{1}$, forced expiratory volume in 1 second; FVC, forced vital capacity; PEF, peak expiratory flow.

* Adjusted for skin color, family income at birth, maternal schooling at birth, birth weight, smoking during pregnancy, mother's height at birth, body mass index at 11 years, body mass index at 15 years, height at 15 years, wheezing in the previous year at 15 years, smoking at 15 years and Tanner stage at 15 years. $P$-value for linear trend. 


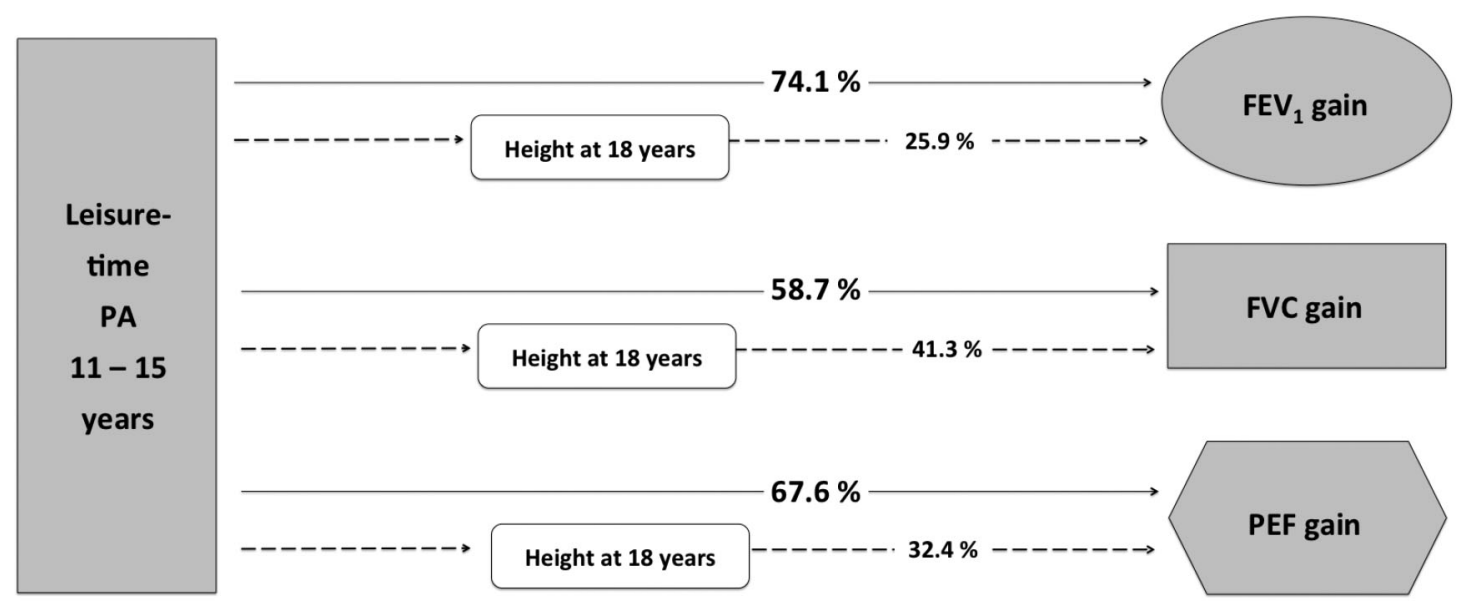

Figure 2 - Direct effect of leisure-time physical activity (active periods from 11 to 15 years) and effect mediated by height at 18 years in the gain of $\mathrm{FEV}_{1}$ (forced expiratory volume in 1 second), FVC (forced vital capacity), and PEF (peak expiratory flow) in male subjects.

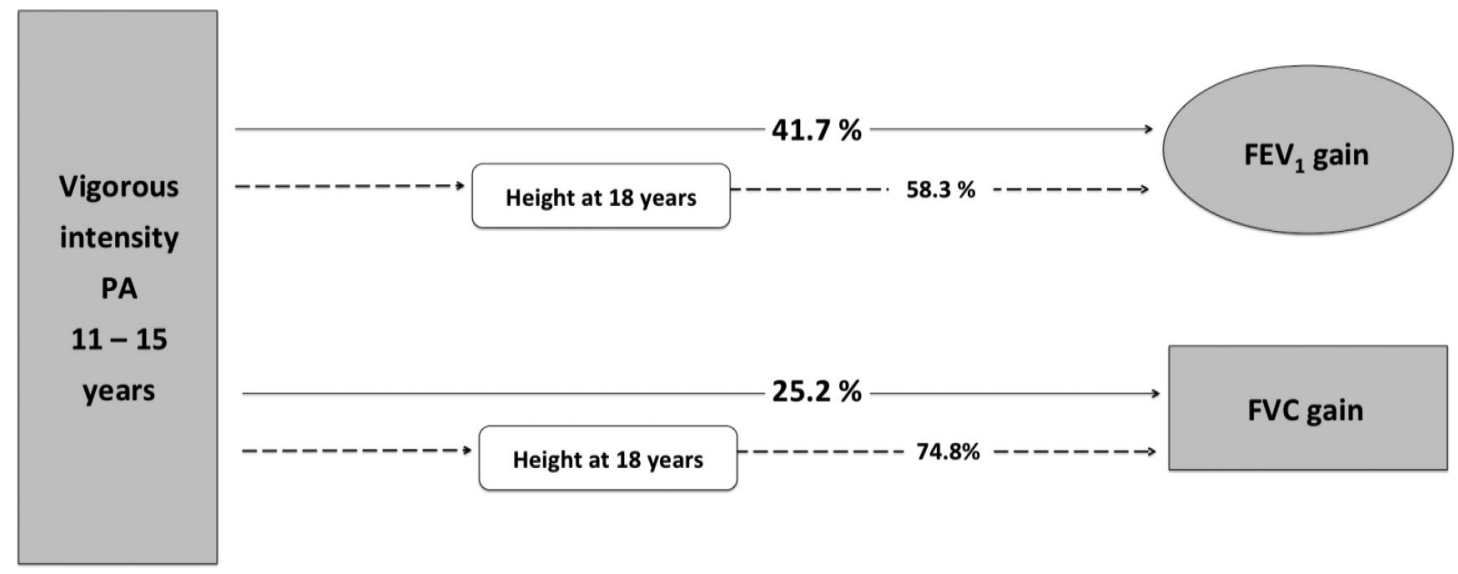

Figure 3 - Direct effect of vigorous-intensity physical activity (active periods from 11 to 15 years) and effect mediated by height at 18 years in the gain of $\mathrm{FEV}_{1}$ (forced expiratory volume in 1 second) and FVC (forced vital capacity) in male subjects.

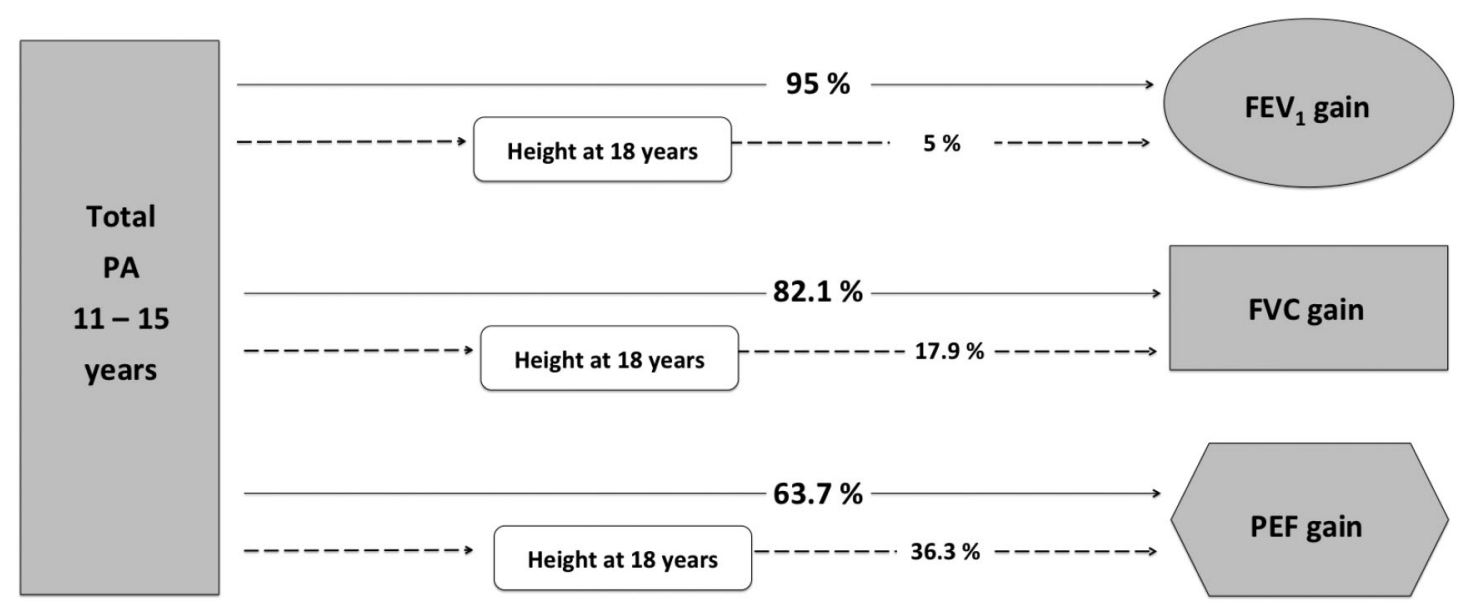

Figure 4 - Direct effect of total physical activity (active periods from 11 to 15 years) and effect mediated by height at 18 years in the gain of FEV (forced expiratory volume in 1 second), FVC (forced vital capacity), and PEF (peak expiratory flow) in male subjects. 

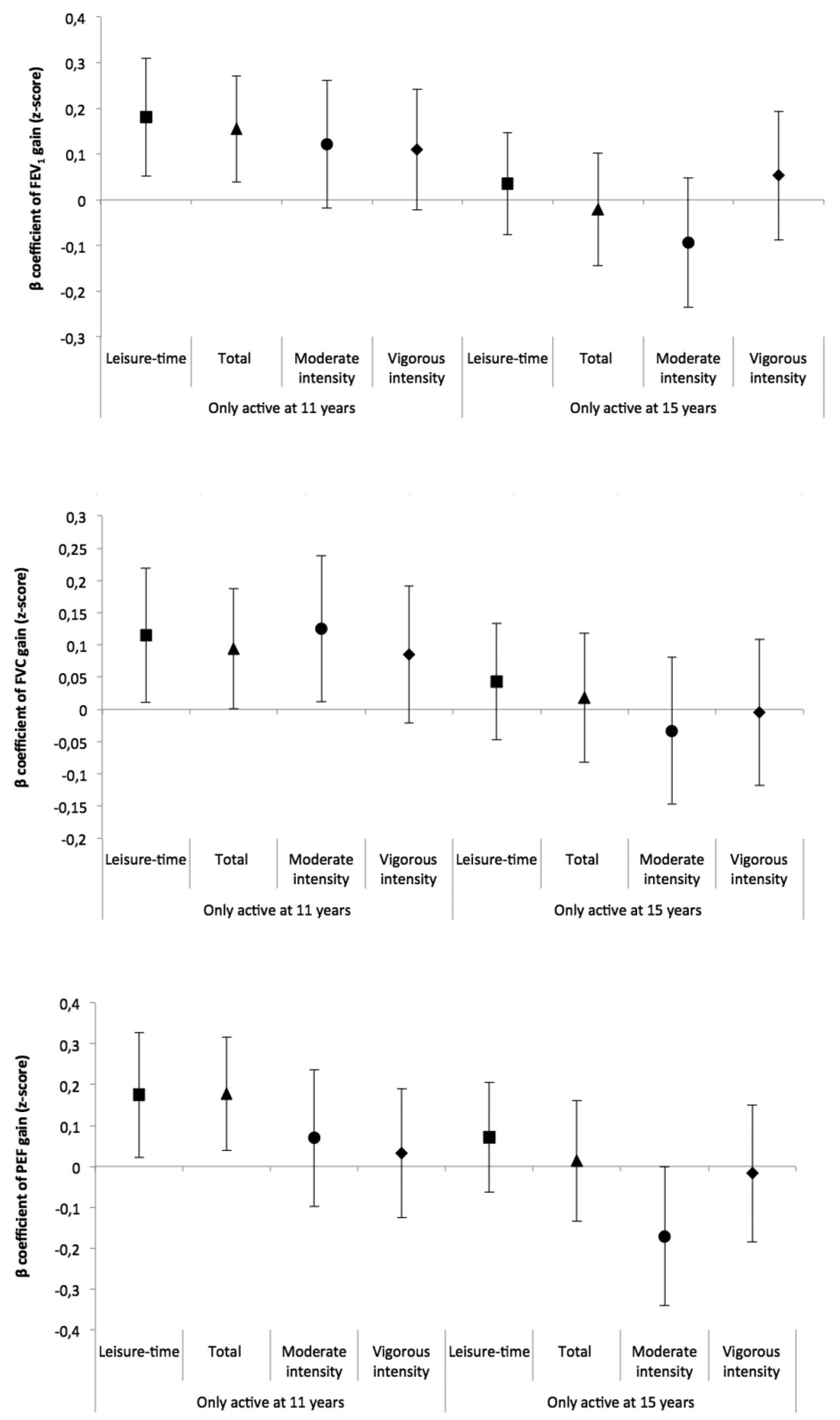

Figure 5 - Adjusted analyses (coefficients and 95\% CI) of the association between only active at age 11 and only at age 15 years and FEV $($ forced expiratory volume in 1 second), FVC (forced vital capacity), and PEF (peak expiratory flow) gains, compared with inactive at ages 11 and 15 years, in male subjects. 
improve $\mathrm{PF}$ are still controversial, the association may be explained by genetic, environmental, and behavioral factors as reported by Eisenmann and colleagues..$^{15}$ One of the explanations deals with the fact that physical activity induces greater respiratory maneuvers and may increase the amplitude of thoracic cage movement, thus leading to greater ventilatory capacity. ${ }^{30}$ Furthermore, it can be argued that PF is associated with physical activity because airway development in early childhood depends on regular expansions of the lungs, which are only attained through exercise..$^{31}$

Our study has several strengths. Primarily, it is a large population-based sample with high rates of retention and follow-up, which minimize the likelihood of selection bias. Furthermore, the longitudinal design of the study allows for the assessment of temporality between the associations of early adolescent physical activity and later adolescent gains in PF. Regarding the spirometric tests data at ages 15 and 18 years, approximately $90 \%$ of the procedures reached the international quality criteria proposed. ${ }^{19}$ Lastly, the study is one of the first of its kind to be conducted in a middle-income country.

However, some limitations must also be taken into account. One such limitation is the lack of PF measures in early adolescence. Moreover, the study relied on self-reported physical activity data, which may lead to a certain level of misclassification or bias. Nevertheless, objective measures also present limitations and questionnaires used to assess physical activity are widely used as a common measure of physical activity in population-based studies. ${ }^{32,33}$ Another possible limitation might be the lack of adjustment for asthma diagnosis or asthma severity in the analysis. This is due to the notion that a higher proportion of asthmatic adolescents in the never-active group could have confounded the results. To control for this, we have adjusted all analyses for wheezing in the past 12 months as a proxy for asthma.

In conclusion, this longitudinal study assessing the association between physical activity and PF gain in adolescents from Brazil noted a positive association between the level of leisure-time and vigorous-intensity physical activity in early adolescence and lung growth in later adolescence in boys that exists over and above the effects of an increase in stature. These findings underscore the positive effects of regular physical activity during growth period on lung development.

\section{Acknowledgments}

The 1993 Pelotas Birth Cohort Study is currently supported by the Wellcome Trust through the program entitled Major Awards for Latin America on Health Consequences of Population Change (Grant: 086974/Z/08/Z). The European Union, National Support Program for Centers of Excellence (PRONEX), the Brazilian National Research Council (CNPq), and the Brazilian Ministry of Health supported previous phases of the study. BGCS received financial support from $\mathrm{CNPq}$ and CAPES Foundation. None of the funding organizations of this study influenced the study design, data collection, data analysis, data interpretation, or writing of the manuscript.

\section{References}

1. WHO. Global Health Risks: Mortality and Burden of Disease Attributable to Selected Major Risks. Geneva: World Health Organization; 2009.

2. Cesa CC, Sbruzzi G, Ribeiro RA, et al. Physical activity and cardiovascular risk factors in children: meta-analysis of randomized clinical trials. Prev Med. 2014;69:54-62. PubMed doi:10.1016/j. ypmed.2014.08.014

3. Lee IM, Shiroma EJ, Lobelo F, et al. Effect of physical inactivity on major non-communicable diseases worldwide: an analysis of burden of disease and life expectancy. Lancet. 2012;380:219-229. PubMed doi:10.1016/S0140-6736(12)61031-9

4. Hallal PC, Andersen LB, Bull FC, et al. Global physical activity levels: surveillance progress, pitfalls, and prospects. Lancet. 2012;380:247257. PubMed doi:10.1016/S0140-6736(12)60646-1

5. Knuth AG, Malta DC, Dumith SC, et al. Practice of physical activity and sedentarism among Brazilians: results of the National Household Sample Survey-2008. Cien Saude Colet. 2011;16:3697-3705. PubMed doi:10.1590/S1413-81232011001000007

6. Knuiman MW, James AL, Divitini ML, Ryan G, Bartholomew HC, Musk AW. Lung function, respiratory symptoms, and mortality: results from the Busselton Health Study. Ann Epidemiol. 1999;9:297-306. PubMed doi:10.1016/S1047-2797(98)00066-0

7. Menezes AM, Pérez-Padilla R, Wehrmeister FC, et al. FEV $\mathrm{FE}_{1}$ is a better predictor of mortality than FVC: the PLATINO Cohort Study. PLoS One. 2014;9:e109732. PubMed doi:10.1371/journal.pone.0109732

8. Mészáros D, Dharmage SC, Matheson MC, et al. Poor lung function and tonsillectomy in childhood are associated with mortality from age 18 to 44. Respir Med. 2010;104:808-815. PubMed doi:10.1016/j. rmed.2009.12.001

9. Holmen TL, Barrett-Connor E, Clausen J, Holmen J, Bjermer L. Physical exercise, sports, and lung function in smoking versus nonsmoking adolescents. Eur Respir J. 2002;19:8-15. PubMed doi:10.1183/0903 1936.02.00203502

10. Malkia E, Impivaara O. Intensity of physical activity and respiratory function in subjects with and without bronchial asthma. Scand J Med Sci Sports. 1998;8:27-32. PubMed doi:10.1111/j.1600-0838.1998. tb00225.x

11. Pitta F, Takaki MY, Oliveira NH, et al. Relationship between pulmonary function and physical activity in daily life in patients with COPD. Respir Med. 2008;102:1203-1207. PubMed doi:10.1016/j. rmed.2008.03.004

12. Pelkonen M, Notkola IL, Lakka T, Tukiainen HO, Kivinen P, Nissinen A. Delaying decline in pulmonary function with physical activity: a 25-year follow-up. Am J Respir Crit Care Med. 2003;168:494-499. PubMed doi:10.1164/rccm.200208-954OC

13. Nystad W, Samuelsen SO, Nafstad P, Langhammer A. Association between level of physical activity and lung function among Norwegian men and women: the HUNT study. Int J Tuberc Lung Dis. 2006;10:1399-1405. PubMed

14. Twisk JW, Staal BJ, Brinkman MN, Kemper HC, van Mechelen W. Tracking of lung function parameters and the longitudinal relationship with lifestyle. Eur Respir J. 1998;12:627-634. PubMed doi:10.1183/ 09031936.98.12030627

15. Eisenmann JC, Katzmarzyk PT, Thériault G, Song TMK, Malina RM, Bouchard C. Physical activity and pulmonary function in youth: The Québec Family Study. Pediatr Exerc Sci. 1999;11:208-217. doi:10.1123/pes.11.3.208

16. Menezes AM, Wehrmeister FC, Muniz LC, et al. Physical activity and lung function in adolescents: the 1993 Pelotas (Brazil) Birth Cohort Study. J Adolesc Health. 2012;51:S27-S31. PubMed doi:10.1016/j. jadohealth.2012.06.023

17. Victora CG, Araujo CL, Menezes AM, et al. Methodological aspects of the 1993 Pelotas (Brazil) Birth Cohort Study. Rev Saude Publica. 2006;40:39-46. PubMed doi:10.1590/S0034-89102006000100008 
18. Goncalves H, Assuncao MC, Wehrmeister FC, et al. Cohort profile update: the 1993 Pelotas (Brazil) Birth Cohort follow-up visits in adolescence. Int J Epidemiol. 2014;43:1082-1088. PubMed doi:10.1093/ ije/dyu077

19. Miller MR, Hankinson J, Brusasco V, et al. Standardisation of spirometry. Eur Respir J. 2005;26:319-338. PubMed doi:10.1183/0903 1936.05.00034805

20. Pereira CAC. Espirometria. J Pneumol. 2002;28:S1-S82.

21. Quanjer PH, Stanojevic S, Cole TJ, et al. Multi-ethnic reference values for spirometry for the 3-95-yr age range: the global lung function 2012 equations. Eur Respir J. 2012;40:1324-1343. PubMed doi:10.1183/09031936.00080312

22. WHO. Global Recommendations on Physical Activity for Health. Geneva: World Health Organization; 2010.

23. Ridley K, Ainsworth BE, Olds TS. Development of a compendium of energy expenditures for youth. Int J Behav Nutr Phys Act. 2008;5:45. PubMed doi:10.1186/1479-5868-5-45

24. Trabelsi Y, Paries J, Harrabi I, et al. Factors affecting the development of lung function in Tunisian children. Am J Hum Biol. 2008;20:716725. PubMed doi:10.1002/ajhb.20804

25. Berntsen S, Wisløff T, Nafstad P, Nystad W. Lung function increases with increasing level of physical activity in school children. Pediatr Exerc Sci. 2008;20:402-410. PubMed doi:10.1123/pes.20.4.402

26. Ji J, Wang SQ, Liu YJ, He QQ. Physical activity and lung function growth in a cohort of Chinese School children: a prospective study. PLoS One. 2013;8:e66098. PubMed doi:10.1371/journal. pone.0066098

27. de Onis M, Onyango AW, Borghi E, Siyam A, Nishida C, Siekmann J. Development of a WHO growth reference for school-aged children and adolescents. Bull World Health Organ. 2007;85:660-667. PubMed doi:10.2471/BLT.07.043497

28. Florindo AA, Guimarães VV, Cesar CL, Barros MB, Alves MC, Goldbaum M. Epidemiology of leisure, transportation, occupational, and household physical activity: prevalence and associated factors. $J$ Phys Act Health . 2009;6:625-632. PubMed doi:10.1123/jpah.6.5.625

29. Samitz G, Egger M, Zwahlen M. Domains of physical activity and allcause mortality: systematic review and dose-response meta-analysis of cohort studies. Int J Epidemiol. 2011;40:1382-1400. PubMed doi:10.1093/ije/dyr112

30. Armour J, Donnelly PM, Bye PT. The large lungs of elite swimmers: an increased alveolar number? Eur Respir J. 1993;6:237-247. PubMed

31. Fredberg JJ, Inouye DS, Mijailovich SM, Butler JP. Perturbed equilibrium of myosin binding in airway smooth muscle and its implications in bronchospasm. Am J Respir Crit Care Med. 1999;159:959-967. PubMed doi:10.1164/ajrccm.159.3.9804060

32. Chinapaw MJ, Mokkink LB, van Poppel MN, van Mechelen W, Terwee CB. Physical activity questionnaires for youth: a systematic review of measurement properties. Sports Med. 2010;40:539-563. PubMed doi:10.2165/11530770-000000000-00000

33. Warren JM, Ekelund U, Besson H, et al. Assessment of physical activity-a review of methodologies with reference to epidemiological research: a report of the exercise physiology section of the European Association of Cardiovascular Prevention and Rehabilitation. Eur J Cardiovasc Prev Rehabil. 2010;17:127-139. PubMed doi:10.1097/ HJR.0b013e32832ed875 